\title{
Difficult Airway for Intubation by Bronchoscopy : Importance of the Functional Anatomy of the Upper Airway
}

Pablo Rubinstein-Agunin*

1 Pulmonology Department, Hospital Universitario General de Cataluña, Spain

*Corresponding author: Pablo Rubinstein-Agunin, MD, PhD, Pulmonology Department, Hospital

Universitario General de Cataluña, Pere i Pons, 1, CP 08195, Barcelona, Spain, Email:pablo.rubinstein@separ.es

Submission: 阱 January 19, 2018; Published: 制April 06, 2018

\section{Case Report}

The difficult airway is a major cause of morbidity and mortality. Its identification allows developing strategies to ensure that a patient who requires it is intubated and ventilated. Intubation with bronchoscope is one of the techniques of choice, and is performed with the patient without muscle relaxation, in spontaneous

ventilation [1]. Functional anatomy of the upper airway may differ when the patient is relaxed or spontaneously ventilated [2]. We present the case of a 58-year-old male patient, smoker of 60 pack-years, snorer, hypertensive and overweight, who underwent a bronchoscopy for hemoptysis, in spontaneous ventilation, and under deep sedation with propofol (Video 1 \& 2).

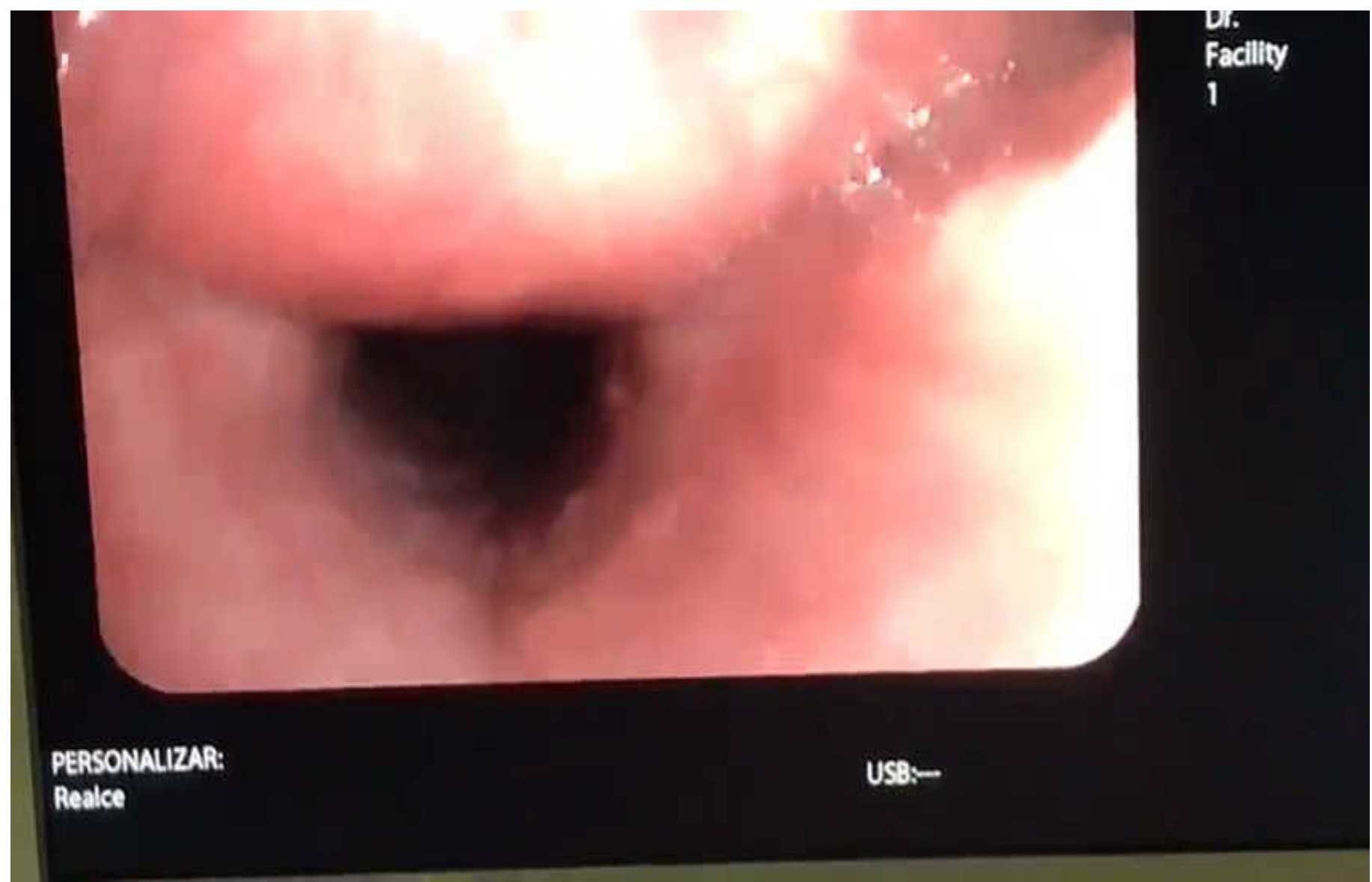



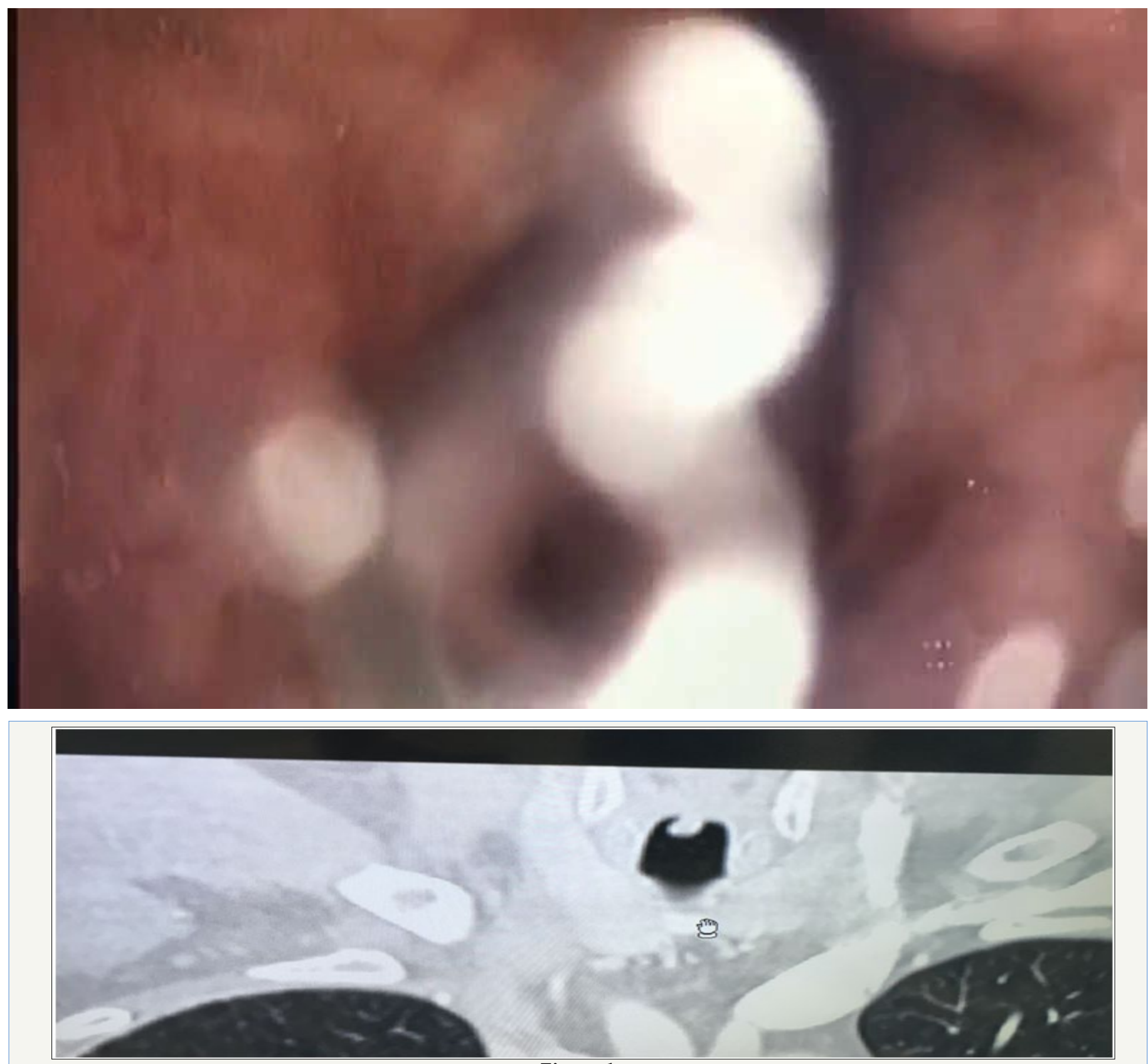

Figure 1

A difficult functional airway was observed at different levels. On the one hand, there is a marked concentric reduction of the caliber of the supraglottic airway, due to hyper laxity of the pharyngolaryngeal walls and the effect of propofol on the gloss opharyngeal muscle (Figure 1). It is also observed a fall of the epiglottis towards the posterior wall, which may be due in part to the position (supine decubitus). Finally, an important edema of Reinke causes an increase in the size of the vocal cords, as well as a valvular mechanism in the left vocal cord (seen in the video), and that in the scanner is seen as a tumor that protrudes through under vocal cords. Functional anatomical variations of the upper airway require quick decisions in the management of these patients. In this case, intubation with bronchoscopy can be difficult, and the technique can be facilitated by relaxing the patient or by using a laryngeal mask.

\section{References}

1. American society of anesthesiologists task force on management of the difficult airway (2013) Practice Guidelines for Management of the Difficult Airway. Anesthesiology 118(2): 1-20.

2. Rubinstein PA, Domenech MLA, Leiro RA (2016) A one-handed maneuver for opening the airway during flexible bronchoscopy under deep sedation. Arch Bronconeumol 52(8): 435. 
Creative Commons Attribution 4.0 International License

For possible submissions Click Here

Submit Article

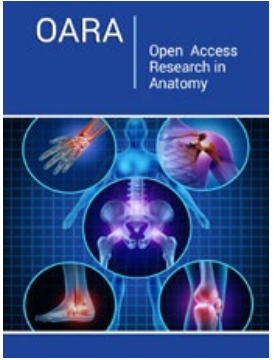

\section{Open Access Research in Anatomy}

\section{Benefits of Publishing with us}

- High-level peer review and editorial services

- Freely accessible online immediately upon publication

- Authors retain the copyright to their work

- Licensing it under a Creative Commons license

- Visibility through different online platforms 